\title{
CONSTRUINDO PONTES: RELATO DE EXPERIÊNCIA DE UMA EQUIPE MULTIDISCIPLINAR EM TRANSTORNOS ALIMENTARES
}

\author{
BUILDING BRIDGES: A MULTIDISCIPLINARY TEAM EXPERIENCE REPORT ON EATING DISORDERS
}

Luciana Maria da Silva1, Manoel Antônio dos Santos²

${ }^{1}$ Psicóloga. Doutoranda em Psicobiologia. Bolsista do CNPq. ${ }^{2}$ Docente. Bolsista de Produtividade em Pesquisa do CNPq. Departamento de Psicologia e Educação. Faculdade de Filosofia, Ciências e Letras de Ribeirão Preto - USP.

Correspondência: Rua Cavalheiro Torquato Rizzi, 1441, apto 13. CEP 14020-300 - Ribeirão Preto-SP.

E-mail: lumarias@usp.br.

Silva LM, Santos MA. Construindo pontes: relato de experiência de uma equipe multidisciplinar em transtornos alimentares. Medicina (Ribeirão Preto) 2006; 39 (3): 415-24.

RESUMO: O objetivo desse estudo é descrever a experiência de multi e interdisciplinaridade vivenciada pela equipe de profissionais de saúde que constitui o Grupo de Assistência em Transtornos Alimentares (GRATA) do Ambulatório de Nutrologia do Hospital das Clínicas da Faculdade de Medicina de Ribeirão Preto-USP. Este artigo focaliza os recursos humanos e os modos de enfrentamento de situações recorrentes da prática assistencial desenvolvidas no contexto ambulatorial e hospitalar. O modelo assistencial proposto pelo GRATA é descrito como exemplo de uma práxis que fixa a interdisciplinaridade como eixo norteador da construção do conhecimento e das ações em saúde, considerando as múltiplas dimensões que envolvem o processo saúde-doença. Um conhecimento vivo é produzido a partir da convergência de múltiplos olhares disciplinares que se intercruzam. São apresentados alguns extratos de experiências que ilustram a busca de ações integradas na prestação de serviços. Assistência, ensino e pesquisa são articulados para a construção da prática assistencial. Observou-se que a equipe de saúde desenvolveu, gradualmente, um comprometimento com os reais interesses e as condições concretas de vida da população. Conclui-se que a abordagem interdisciplinar é a que mais se aproxima da visão da complexidade que caracteriza os cuidados em saúde, numa tentativa de superação do enfoque biomédico, remediativo e fragmentado, no campo dos transtornos alimentares.

Descritores: Equipe Multidisciplinar. Transtornos da Alimentação. Anorexia Nervosa. Bulimia Nervosa.

O tratamento de pacientes com transtornos alimentares - anorexia e bulimia nervosas - constitui-se em um grande desafio para os profissionais da área da saúde em geral. As evidências acumuladas na literatura científica mostram que estes transtornos requerem a atenção de uma equipe multiprofissional. Dada a complexidade com que se apresentam e da multiplicidade de áreas do comportamento humano que são afetadas - física, psicológica, social, cultural, econômica - essas síndromes psicossomáticas de etiopatogenia multifatorial dificilmente podem ser tratadas por um profissional isoladamente.
$\mathrm{Na}$ contemporaneidade tem-se observado um aumento considerável na prevalência de casos de transtornos alimentares, incidindo cada vez mais em idades precoces, principalmente em adolescentes do sexo feminino. Na sociedade capitalista ocidental parece prevalecer, no imaginário coletivo, um padrão de beleza que se impõe especialmente às mulheres, para as quais a aparência física representa uma importante medida de valor pessoal ${ }^{1}$.

As manifestações psicopatológicas que configuram as categorias diagnósticas de anorexia e bulimia nervosas freqüentemente são desencadeadas por 
situações associadas ao desejo de se ter um corpo perfeito e sem "falhas", identificado com um corpo esbelto, esguio, quando não esquálido. Nota-se uma tendência de seguir regras de beleza ditadas pela mídia, que fomentam o desejo de ser magro a todo custo. Na busca de alcançar esse ideal de ego, pautado em uma meta de magreza que se radicaliza à medida que a doença se agrava, tornando-se cada vez mais inatingível, os pacientes pagam um preço muito alto, em alguns casos extremos com a própria vida. O comprometimento severo do estado nutricional desencadeia uma série de complicações físicas, que se adicionam às graves perturbações emocionais que acometem esses pacientes.

Os estudos epidemiológicos mostram que, geralmente, a anorexia nervosa tem início nos primeiros anos da adolescência, entre 13 e 18 anos de idade, e afeta cerca de $0,5 \%$ das mulheres, com número crescente de casos entre homens. Já a bulimia nervosa atinge de $1 \%$ a $2 \%$ da população, também com maior prevalência de pacientes do sexo feminino, em uma proporção de 9:1. Seu aparecimento tende a ser mais tardio, variando desde os últimos anos da adolescência até os quarenta anos de idade ${ }^{2,3}$.

Esses transtornos têm uma apresentação semelhante do ponto de vista sintomatológico em nível psíquico, como marcada distorção da imagem corporal, medo mórbido de engordar, preocupação excessiva com os alimentos e desejo constante e irrealista de emagrecer, independentemente da estratégia utilizada para se atingir esse objetivo. Considerando-se o estágio do ciclo vital em que incidem - geralmente na adolescência - esses quadros afetam gravemente o desenvolvimento do indivíduo e podem desencadear conseqüências graves, inclusive com risco iminente de morte ${ }^{4}$.

$\mathrm{Na}$ anorexia nervosa há uma redução voluntária e drástica da ingestão alimentar, com perda progressiva e intensamente desejada de peso, caquexia e inanição e, em alguns casos, a morte ${ }^{5}$. Já na bulimia nervosa, basicamente tem-se uma compulsão alimentar periódica, caracterizada pela ingestão, em um período limitado de tempo, de uma quantidade de alimento definitivamente maior do que a maioria dos indivíduos consumiria sob circunstâncias similares, seguida de métodos compensatórios para evitar o ganho de peso - comportamentos purgativos, tais como indução de vômitos, uso indevido de laxantes, diuréticos, enemas e exercícios físicos em exagero.

Em decorrência da complexidade dos sintomas já referidos, freqüentemente se observa uma dificul- dade de delimitar uma estratégia assistencial que permita abordar eficientemente esses pacientes e suas famílias, que se mostram muitas vezes desconfiados e descrentes no tratamento. Na maioria das vezes os pacientes não admitem sua doença nos estágios iniciais do tratamento e só chegam a formular um pedido de ajuda depois de um certo tempo. Isso explica porque eles geralmente não fazem demanda espontânea de ajuda profissional, mas são trazidos por alguém próximo, geralmente os familiares.

Diante de quadros tão graves pode-se perguntar: o que leva uma pessoa a tal condição de deterioração física e mental? Várias são as hipóteses sobre os possíveis fatores que concorrem para a etiologia do quadro, contudo os estudos concordam que nenhum fator isolado pode ser considerado a priori e por si só desencadeante desses transtornos ${ }^{5,6}$. Entre as hipóteses de etiopatogenia, pode-se aventar aspectos sócioculturais específicos, disfunções da interação familiar, possíveis eventos estressantes relacionados à sexualidade e à formação da personalidade, dificuldades em aceitar a própria sexualidade, as vicissitudes do crescimento e o processo de individuação e diferenciação em relação à figura materna ${ }^{7}$.

Além do acometimento pessoal, os transtornos alimentares também geram intenso sofrimento e desgaste emocional nas pessoas que compõem a rede social significativa do paciente, como a família. Os sintomas, como permanecer em jejum por longos períodos ou comer em excesso e vomitar em seguida, dificilmente são compreendidos adequadamente por um ou mais membros da família, gerando mais situações estressantes tanto para os pacientes quanto para os familiares ${ }^{8}$. Os impasses vivenciados no plano das relações familiares potencializam conflitos latentes e criam outros novos, corroendo os vínculos e infligindo dor psíquica nos cuidadores.

Os diversos sintomas apresentados pelos pacientes, bem como as complicações deles advindas - seja diretamente para eles, seja para as famílias - e a complexidade da situação biopsicossocial que geralmente envolve esses transtornos exige um tratamento altamente especializado. A estratégia de tratamento deve considerar o indivíduo como um todo, sem perder de vista os diversos contextos - macro e microssocial - nos quais ele está inserido: familiar, psicológico, sócio-cultural, econômico, incluindo cuidados dispensados à sua organização familiar ${ }^{9}$.

Os profissionais envolvidos na difícil tarefa de diagnosticar, planejar e dar continuidade ao trata- 
mento de pacientes portadores de anorexia e bulimia nervosas devem estar cientes de que precisam manter um constante diálogo, discutindo cada caso com especial atenção, sabendo que, nesse campo de ação, o contato com o "novo", mais do que um elementosurpresa, é um fator desestabilizador muito presente e recorrente.

Nesse sentido, como preconiza a literatura ${ }^{2,5,10}$, o trabalho em equipe multidisciplinar enseja a oportunidade de se construir uma visão global de cada caso mediante uma interlocução entre os diferentes profissionais envolvidos no seguimento terapêutico, contribuindo para alcançar um melhor prognóstico para os pacientes e deter o curso crônico a que freqüentemente esses transtornos tendem. A sistematização do trabalho integrado da equipe também contribui para o avanço dos tratamentos nesse campo de intervenção em saúde.

\section{1- PRODUÇÃo de SABERES E PRÁTICAS EM SAÚDE NA ÓTICA INTERDISCIPLINAR}

A interdisciplinaridade impõe que se estabeleçam múltiplas interconexões entre as diversas disciplinas para que as ações se efetivem na promoção dos cuidados em saúde. Essa ótica se contrapõe à concepção fragmentada que impera nas instituições de saúde e que se firmou historicamente com o advento da medicina científica.

A produção de saberes e práticas em saúde é fragmentada ${ }^{11}$ e ainda muito centrada em ações de prevenção e controle de agravos pontuais. Os enfoques utilizados freqüentemente desconsideram a realidade vivida pelos sujeitos. Recentemente tem se constituído um movimento crítico-reflexivo, oriundo de diversas áreas do saber, que problematiza os modelos consagrados de assistência. Esse pensamento crítico incide tanto no plano epistemológico como pragmático, questionando os alicerces conceituais que sustentam o trabalho em saúde. Alinhados a esse movimento reflexivo, os novos paradigmas que introduzem visões alternativas de mundo e de fenômeno humano, diferentes das tradicionais, têm propiciado o reconhecimento das potencialidades de constituição de um conhecimento interdisciplinar ${ }^{11,12}$. Neste sentido, a ação intersetorial têm ganhado força nos últimos anos, na medida em que se fixa a interdisciplinaridade como eixo norteador da construção do conhecimento e das práticas em saúde, considerando as múltiplas dimensões que envolvem o processo saúde-doença.
Somente um trabalho de efetiva integração e o estabelecimento de inter-relações entre as diversas disciplinas proporcionará a criação de condições propícias para enfrentar a complexidade do cuidar pensado como integralidade. Nesse sentido, acreditamos que a busca de ações integradas na prestação de serviços e a associação entre assistência, ensino e pesquisa são estratégias importantes para a construção de uma prática assistencial realmente comprometida com os interesses e as condições concretas de vida da população.

Desse modo, uma abordagem interdisciplinar é a que, em nossa compreensão, mais se aproxima do olhar da complexidade que caracteriza os cuidados em saúde, como resposta à crescente compartimentalização do saber, numa tentativa de superação do enfoque biomédico, curativista e fragmentado que têm sido adotado no tratamento dos transtornos alimentares.

\section{2- O MODELO ASSISTENCIAL DO GRATA: UM CONTÍNUO MOVIMENTO DE CONS- TRUÇÃO, DESCONSTRUÇÃO E RECONS- TRUÇÃO DAS PRÁTICAS}

A experiência vivenciada pelo Grupo de Assistência em Transtornos Alimentares do Ambulatório de Nutrologia do Hospital das Clínicas da Faculdade de Medicina de Ribeirão Preto-USP tem mostrado como a equipe multidisciplinar constrói sua caminhada por meio do diálogo permanente entre os diferentes profissionais envolvidos no tratamento dos pacientes.

O modelo assistencial adotado alinha-se a uma perspectiva que privilegia um olhar abrangente em direção à problemática, que vem sendo modelado e remodelado com a experiência adquirida ao longo dos anos. O grupo é composto por diferentes profissionais: médicos nutrólogos, nutricionistas, psiquiatras, psicólogos e estudantes-estagiários de Psicologia, além de enfermeiros e terapeutas ocupacionais nos casos que requerem internação. Os profissionais atuam, em sua maioria, em caráter voluntário e estão inseridos em uma instituição macro-hospitalar pública, de natureza acadêmica, atendendo diferentes camadas sociais dada a sua inserção no Sistema Único de Saúde. Cada integrante desempenha um papel essencial no cuidado do paciente e/ou dos familiares e acompanhantes, respeitando-se o saber de cada um e sua colaboração para o tratamento global.

Tais enfermidades desafiam constantemente os saberes dos profissionais que se dispõem a enfrentá-las, 
uma vez que os pacientes não respondem de maneira uniforme e constante ao arsenal terapêutico tradicional do modelo biomédico. A experiência referenda que, nesse campo de intervenção, é preciso oferecer uma gama diversificada de recursos técnicos e humanos para lidar com os desafios colocados pela prática.

Do ponto de vista da assistência, as modalidades de atendimento oferecidas pelo GRATA, em nível ambulatorial, com funcionamento semanal, são: atendimento clínico individual (realizado por médicos nutrólogos e por nutricionistas), atendimentos psiquiátrico, atendimentos psicoterápicos individuais (para pacientes e alguns familiares) e psicodiagnóstico (para a compreensão do funcionamento mental do paciente). Quando há necessidade de internações (que ocorrem na enfermaria da Nutrologia) há também a participação de terapeutas ocupacionais, médicos clínicos gerais, enfermeiros e demais profissionais envolvidos na assistência do caso em questão.

Preconizando uma atenção especial aos familiares e acompanhantes também é oferecido semanalmente, no ambulatório, um grupo de orientação médico-nutricional, seguido por um grupo de apoio psicológico aos cuidadores ${ }^{13,14,15}$.

No decorrer desses atendimentos, no contato direto com pacientes e seus cuidadores, podem ser percebidas as dificuldades, angústias, temores e mazelas no lidar com esses tipos de transtornos. Também se percebe o quanto os diferentes cuidados e as distintas visões que se têm de um mesmo paciente ou família são importantes para a compreensão integral do caso. Como não há uma receita ou fórmula geral a ser seguida, a maneira que o grupo encontrou de refletir sobre os atendimentos foi manter um contato muito próximo entre seus membros, constituindo parcerias em todas as modalidades de assistência.

Assim, médicos e nutricionistas dividem o grupo de apoio aos familiares e também atendimentos individuais; psicólogos e nutricionistas realizam reuniões nucleares com a família; psicólogos e/ou estagiários de Psicologia observam os grupos de apoio a pacientes e familiares, bem como as consultas individuais conduzidas pela nutricionista ou médico. Desse modo, várias possibilidades de combinação são experimentadas simultaneamente, dosadas de acordo com as necessidades de cada caso. Posteriormente, os resultados são socializados com o restante da equipe nas discussões que ocorrem durante as reuniões semanais.

Essa reunião foi a estratégia que os membros do GRATA encontraram para levar adiante sua tarefa assistencial, buscando-se explorar os recursos criativos que são potencializados na reflexão compartilhada sobre o trabalho interdisciplinar. Essas reuniões ocorrem em um tempo médio de duas horas. Nelas são discutidos os casos atendidos durante a semana (tanto em nível ambulatorial como na internação, quando é o caso), assim como os grupos de familiares e de pacientes. Diferentes pontos de vista são levantados e analisados por todos, sendo que toda opinião emitida é considerada uma contribuição relevante a ser levada em conta no planejamento e seguimento dos casos.

Acredita-se que neste campo de atuação a comunicação exerce um papel fundamental. Poder "falar a mesma língua" é uma meta constantemente perseguida pelos membros da equipe, pois se percebe que existe uma necessidade dos pacientes e/ou familiares averigüar condutas, orientações ou indicações terapêuticas com mais de um profissional envolvido no seguimento. Muitas vezes esses profissionais são colocados em "cheque" por um ou outro paciente e, se não tiverem em mente uma mesma conduta a ser tomada (que muitas vezes é exaustivamente discutida nas reuniões de equipe), contribuem para aumentar a confusão de pacientes e familiares e, conseqüientemente, minar o sentimento de confiança na equipe. Todo cuidado é pouco quando se trata de lidar com pacientes com um grau de desconfiança elevado.

No decorrer desses encontros também são discutidos aspectos da evolução do processo psicoterapêutico individual de pacientes e pais, levado a cabo por psicólogos e estagiários integrantes do GRATA ou por outros profissionais extra-equipe envolvidos e que são convidados a participarem das reuniões, quando se julga conveniente. Nessas reuniões toma-se sempre o cuidado de se preservar o compromisso com o sigilo que caracteriza o contrato terapêutico, mantendo-se o foco voltado para aspectos dos psicodinamismos individuais e familiares do portador do transtorno e/ou de seu familiar. Dúvidas, questionamentos e considerações acerca de cada paciente são discutidas quase que exaustivamente, oferecendo ao paciente $\mathrm{e}$ seus familiares a atenção global de que necessitam.

Nessas reuniões que envolvem toda a equipe há uma preocupação de se fomentar condições propícias para que se crie a possibilidade de se perceberem as falhas e lacunas nas condutas da equipe, sendo que dificuldades podem ser gradualmente repensadas e reavaliadas, almejando a melhoria da qualidade dos atendimentos, em todas as suas modalidades. Por conta das peculiaridades enfrentadas no cotidiano profissio- 
nal, muitas vezes surgem questionamentos sobre a necessidade de a própria equipe também "ser cuidada". Mesmo nas situações de impasse, potencialmente estressantes para a equipe, são discutidas quais seriam as possibilidades de atender as reais demandas do grupo.

Ao longo dos anos o GRATA aprendeu e ainda tem aprendido intensamente com esses encontros. Afinal, a partir deles é que podem ser discutidas questões cruciais, tais como: quais são as modalidades de atendimento mais adequadas para a população assistida pelo serviço? Qual a efetividade das intervenções em grupo (de familiares e pacientes)? Quais os critérios de internação e de alta que devemos seguir? Como se faz uma preparação para internações consideradas difíceis? E os encaminhamentos à psicoterapia de pacientes e/ou pais? E como equacionar a questão da medicação com os manejos clínicos e nutricionais, dentre outras decisões acerca do tratamento de cada paciente?

O exercício da interdisciplinaridade é muito exigente. O momento do encontro não é resultado de um desdobramento natural, mas deve ser pacientemente construído pela equipe interdisciplinar. É fruto laborioso de um processo incessante de treinar o olhar para rastrear os fenômenos que se desvelam diante de nós. É aprender a observar a si mesmo enquanto se olha para o outro. E aprender também a olhar para o outro ao olhar para si. Atuar enquanto equipe integrada e afinada com os mesmos pressupostos teórico-clínicos exige muito trabalho, dedicação e fé na capacidade coletiva de gerir problemas humanos. Muitas vozes e timbres diferenciados se fazem ouvir, tentando se aproximar de um uníssono no tratamento. Mixar tantas vozes, combinar tantos olhares que sustentam pontos de vista por vezes muito distintos, é uma tarefa árdua. Contudo, se bem orquestrados os instrumentos que compõem o arranjo musical, a polifonia possibilita um crescimento de todos os naipes da orquestra, ou seja, os membros da equipe podem se enriquecer mutuamente, ampliando as visões acerca da problemática tratada, porém mantendo sua voz própria e sua entonação, que é única.

Uma condição imprescindível para tanto é que se preserve o clima respeitoso em que todas as diferenças podem ser escutadas e acolhidas sem constrangimento, de modo a se manter um diálogo permanente e aberto entre as diferentes especialidades que lidam com os problemas da conduta alimentar. Assim, pode-se melhorar não somente a qualidade de vida de quem é cuidado, como também a de quem cuida.
O trabalho em equipe no contexto de uma instituição-escola é um recurso valioso para a qualificação de profissionais competentes para a produção de cuidados na perspectiva da integralidade da assistência em saúde, como apontam estudos recentes ${ }^{16}$. É no dia-a-dia que nós, trabalhadores de saúde, estamos aprendendo mais e mais com esses intrigantes pacientes, tentando construir fazeres e saberes mais úteis e adequados às suas condições reais de existência, sem deixarmos a retaguarda desguarnecida, isto é, sem esquecermos que nosso olhar alcança até onde nossa miopia nos permite enxergar.

\section{3- ILUSTRAÇÃO CLÍNICA: DA EQUIPE- QUE-CUIDA-DA-EQUIPE À EQUIPE-QUE- CUIDA-DE-SI-MESMA}

Para ilustrarmos o modo como a equipe instituiu uma estratégia de autocuidados, analisaremos uma situação específica. Para preservar o anonimato, os participantes serão identificados apenas pela profissão. A reunião da equipe em foco ocorreu em $10 \mathrm{de}$ outubro de 2003 e foi coordenada por um psicólogo e uma nutricionista do GRATA (doravante referidos como Coordenador e Coordenadora). Naquela ocasião participaram da reunião dois médicos nutrólogos (um médico e uma médica), três profissionais psicólogos (duas psicólogas e um psicólogo) e seis estagiárias do curso de Psicologia. O objetivo era propiciar reflexão e melhor compreensão da realidade dinâmica e complexa do trabalho.

A equipe havia decidido que integrantes da própria equipe se revezariam no papel de coordenação sempre em dupla - de uma reunião ao mês na qual nos dedicaríamos a "cuidar de nós mesmos", enquanto cuidadores. Essa decisão foi resultado do trabalho desenvolvido por cerca de um ano por uma equipe de profissionais do Instituto Familae, que a nosso convite pôs em prática uma modalidade de intervenção denominada Multiplicadores Reflexivos, que tem por objetivo contribuir para o desenvolvimento de recursos e habilidades de enfrentamento em equipes que trabalham particularmente sob condições difíceis, no limite entre a vida e a morte.

Os coordenadores lembraram aos presentes que, alguns meses atrás, na última reunião em que a equipe contou com o suporte da equipe do Familae, foi solicitado que cada membro da equipe escrevesse uma mensagem que gostaria de deixar para o grupo. Do ponto de vista simbólico, era uma espécie de lega- 
do que a equipe de cuidadores, que encerrava seu trabalho conosco, deixava para a equipe do GRATA que, doravante, prosseguiria sem o acompanhamento sistemático do Familae, uma vez que se considerou que os próprios integrantes da equipe já tinham condições de sustentarem a continuidade do trabalho reflexivo. Esses escritos foram depositados em uma pequena caixa, que ficou de posse do grupo como um depositário fiel dos recursos que o próprio grupo foi capaz de produzir naquele período para enfrentar suas dificuldades e prosseguir caminhando juntos.

Os coordenadores da reunião de 10 de outubro resgataram essa caixa, e iniciaram o exercício colocando-a no centro do círculo formado pelas pessoas que constituíam o grupo naquela reunião. O psicólogo indagou:

Coordenador: Quem daqui participou da última reunião com o Familae? (A maioria dos participantes levantou a mão.) Penso que essa caixa tem um significado diferente para quem participou e para quem não participou. Para quem participou, deve ter um significado de conter lembranças, sentimentos compartilhados num determinado momento de nosso percurso... Já para quem não participou, pode ter outros significados: curiosidade sobre o que representa essa caixa, desejo de saber o que ela conteria... Gostaríamos que vocês olhassem agora para essa caixa e tentassem identificar que lembranças vêm à cabeça de vocês e que sentimentos estão associados a essas lembranças. Que cenas estão associadas a essa caixa, a que emoções elas remetem e com quem foram vivenciadas? Para os que não participaram da reunião com o Familae, o que imaginam que essa caixa contém? Que fantasias vocês têm sobre o seu conteúdo?

Coordenadora: $\mathrm{Ou}$ o que gostariam de tirar de dentro dela? Ou de pôr nessa caixa? Vamos dar alguns minutos pra vocês pensarem...

[Silêncio. Depois de mais ou menos 5 minutos:]

Coordenadora: Vamos agora conversar sobre o que cada um pensou. Quem gostaria de começar?

Psicóloga 1: Tem muito de esperança nessa caixa. Acho que de crescimento do grupo.

Coordenadora: E o que gostaria de tirar ou colocar nessa caixa?

Psicóloga 1: Colocar contribuições e tirar estereótipos que às vezes eu sinto que aqui a gente tem em relação aos pacientes e familiares.

Coordenadora: Seriam os "rótulos"? Sente que tem muito disso no grupo?

Psicóloga 1: No tratamento com o paciente.
Mas não só lá, sinto que aqui também tem. Tanto entre a equipe como na relação com o paciente.

Coordenadora: Alguém mais gostaria de falar?

Estagiária 1: Lembrei que naquele dia foram depositados na caixa tanto agradecimentos como expectativas em relação ao grupo.

Coordenadora: E você imagina alguma coisa que poderia estar colocando hoje?

Estagiária 1: Eu depositei, como expectativa minha, a possibilidade de ter mais contato com determinados aspectos... E isso está sendo possível... sinto que estou conseguindo graças ao grupo. Então hoje eu queria trocar aquilo que era expectativa por agradecimento.

Coordenadora: Equal é o sentimento que vem junto com isso?

Estagiária 1: Um sentimento bom, de realização, porque naquele dia, como foram depositadas várias expectativas... agora poder olhar para a expectativa hoje e dizer: puxa, deu certo! Não só comigo, foi uma conquista do grupo.

Coordenadora: Você colocaria mais algum pedido hoje?

Estagiária 1: Não.

Médica: Olhar para a caixa foi lembrar do que foi antes da caixa... O início do trabalho do Familae foi muito bom para a equipe e para meu relacionamento com minha colega de Residência... para eu poder olhar para questões que ficam lá no fundo, muito escondidas, e que geram rixas, mal-estar, por não ter essas questões resolvidas... Foi um tempo de aprendizagem para mim como médica e de todos os colegas da equipe inteira, não só dessa parte da equipe aqui, mas da outra parte inclusive.

Coordenadora: Você está dizendo que conseguiu multiplicar o que aprendeu aqui para outros colegas da equipe?

Médica: Sim.

Psicólogo: Aliás, o trabalho do Familae se chama justamente Multiplicadores Reflexivos.

Médica: Quanto a deixar na caixa, não tem o que deixar aí, já está guardado: aquele tempo e as dúvidas daquele tempo. $\mathrm{E}$ as expectativas agora são outras, não são mais as daquele tempo, mudaram... Expectativas de que o grupo continue assim, apesar de eu não estar aqui mais aqui daqui a pouco... [emociona-se e começa a chorar] Vou sentir falta do carinho... do único lugar onde eu me senti acolhida quando cheguei aqui. Desculpa... 
Coordenadora: Sentimento não tem desculpa, né? Quando aparece, tem de deixar sair...

Coordenador: Quando você fala que as expectativas mudaram, o que quer dizer com isso?

Médica: Aquelas expectativas que eu tinha, eu supri.

Coordenador: Sua fala é parecida com a da [nome da Estagiária 1], que agora troca as expectativas por crescimento, agradecimento?

Médica: Também.

Estagiária 2: Eu não estive na reunião do Familae, mas me lembro que a [uma das coordenadoras daquela reunião] disse que essa caixa teria mensagens que as pessoas poderiam pegar quando sentissem necessidade... e que viriam das pessoas da própria equipe...

Coordenadora: Deu vontade de abrir a caixa? [É preciso sublinhar que a caixa permanecia intocada até esse momento da reunião.]

Estagiária 2: Deu. E de encontrar algo nutritivo.

Coordenadora: E você fantasiou alguma mensagem que poderia estar nessa caixa?

Estagiária 2: Não sei se lembram de antigamente, que tinha o passarinho [periquito] com uma caixa de mensagem [realejo].

Coordenadora: Imaginou qual seria a mensagem?

Estagiária 2: Não.

Psicóloga 2: Também não estive na reunião do Familae. Eu acredito que o que tem dentro é algo que sustenta. E imaginei os atendimentos, em que as pacientes às vezes se mostram como caixas fechadas, com coisas muito pesadas dentro que elas têm medo de abrir. E a gente poderia tentar descobrir não só o que elas têm de pesado, mas também outras coisas que elas têm dentro de si. E nós também, muitas vezes, somos como caixas, então, que receptáculo a gente tem para oferecer? Às vezes é difícil de esperar para ver o que elas têm... às vezes a gente se sente tão perdida que precisa de um olhar estereotipado para dar conta... Isso acontece no grupo e lá fora...

Coordenador: Então a caixa parece ter dois sentidos: de algo cheio de mistérios, que você pode tirar de dentro dela, e também de algo que serve para receber e acolher. Alguém mais gostaria de falar sobre o que pensou?

Estagiária 3: Acho que, porque não estive na reunião do Familae, ou porque eu tenho estado muito autocentrada, quando pediram para eu imaginar algo da caixa pensei em alguma coisa minha: infância, brinquedo, família, felicidade... Achei que dentro da caixa tinha um caleidoscópio... Esse grupo foi bom para mim porque colocou a Psicologia na prática... é a visão do caleidoscópio, você tenta ver alguma coisa através dele e ainda é algo que traz muita fascinação, mistério, dúvida...

Coordenador: Esses sentimentos têm algo a ver com sua posição aqui nesse grupo?

Estagiária 3: Com certeza. Estou descobrindo um novo mundo, que tem a ver com a teoria, mas ao mesmo tempo é diferente...

Coordenadora: Acho que você está falando de sentimentos e emoções que ficam contidos na caixa de cada um de nós e que, através de um símbolo, a gente consegue nomear...

Psicólogo: Gozado que eu não me lembrava mais que na caixa tinha o que a [Estagiária 1] falou: expectativas e agradecimentos, eu me lembrava apenas que aí [nomeia as profissionais do Familae] disseram que ficariam as mensagens que cada membro do grupo deixaria para os demais e que poderiam ser consultadas a qualquer momento que alguém precisasse.

Coordenador: Mais alguém gostaria de compartilhar com o grupo o que pensou ou o que sentiu? [ninguém se pronuncia] Então eu gostaria de retomar o que vocês falaram. [Está posicionado ao lado da lousa branca, onde havia feito anotações resumidas de alguns conteúdos das diversas falas.] A primeira coisa que me ocorreu foi que vocês estão sentados em um lugar, cada um tem um ângulo de visão dentro do círculo diferente do outro, portanto, olham para a caixa de um modo diferente, dependendo de onde estão. As associações, pensamentos e sentimentos em relação à caixa tem a ver com a posição que vocês ocupam dentro do grupo, ou seja, dentro da equipe, e com a posição pessoal de vocês, que tem a ver com a história de cada um: a infância, sua bagagem de experiências, que se refletem quando olham para o grupo... Estou ressaltando nossas diferenças. Pensei nisso por causa do caleidoscópio. Cada um vai ter uma condição de olhar para essa experiência do grupo de um jeito. Isso me fez pensar nos tempos diferentes de cada um: há quem está chegando, e portanto está numa posição de quem agora está só começando a olhar para o trabalho; há quem está envolvido há mais tempo e se sente mais fortalecido nessa posição... Mas um sentimento freqüente que apareceu foi a expectativa de crescimento 
- como na fala da [Psicóloga 1] - ou de que se continue com esse crescimento - como surgiu na fala da [médica]. Aliado a essa expectativa, há esperança de encontrar recursos dentro dessa caixa - que representa simbolicamente o próprio grupo, recursos que ajudem a dar continuidade ao nosso crescimento.

Nesse ponto a reunião caminhou para seu segundo momento:

Coordenador: Nesse segundo momento, a gente podia abrir a caixa, porque esse foi o desejo expresso por alguns de vocês... para que pudéssemos continuar relembrando, como se a caixa fosse um túnel do tempo, um portal do tempo e, através dele, a gente pudesse retornar no tempo.

Coordenadora: Alguém tem alguma idéia de como iniciar essa abertura? Imaginamos que vocês mesmos poderiam propor uma maneira.

Estagiária 3: Estou pensando que, se a gente fosse criança diante de um presente, todas iam querer se lançar... com voracidade. [risos]

Médica: Alguém poderia se manifestar e tomar a iniciativa de abrir e mostrar para as outras pessoas, ler todas as mensagens.

Psicóloga 1: Quem gostaria de abrir?

Psicólogo: Eu não faço questão.

Psicóloga 2: E se cada um abrir à sua maneira?

Médica: Depois da colocação da [Estagiária 3], eu pensei em abrir e dividir com todo mundo.

Psicóloga 1: Eu pensei que... fiz a fantasia que vocês colocaram aí coisas novas... se não colocaram, tem coisas que foi em junho, julho... faz tempo já... tem pessoas que já nem estão aqui mais [na equipe]... porque o que tá aí dentro já fomos trabalhando de alguma maneira nesses meses... Então o que a gente, que está aqui hoje, gostaria de fazer? Aqui tem gente que está chegando, gente que não estava naquele momento, gente que se esqueceu do que estava aí dentro...

Por fim, o grupo decidiu pela abertura da caixa, entendendo, contudo, que o principal já havia acontecido no movimento desse exercício grupal em que a atitude reflexiva - voltar-se para a caixa e cogitar sobre seus conteúdos - era, de certo modo, voltar-se para si mesmo, suas próprias expectativas, percepções, emoções, sentimentos, enfim, o lugar que cada um sentia que ocupava enquanto integrante da equipe.

\section{4- A EQUIPE REUNIDA: O GRUPO COMO CONTEXTO PARA A RESSIGNIFICAÇÃO DE MÚLTIPLAS EXPERIÊNCIAS}

Esse exemplo mostra o quanto o grupo de apoio pode fornecer um contexto útil para a recriação de significados, permitindo levantar hipóteses em busca de um entendimento mais ampliado das experiências emocionais dos membros que compõem a equipe. Porém, para que esse fazer grupal seja realmente operativo é preciso que também haja capacidade de acolhimento por parte de todos, como se vê no exemplo referido, em que foi preciso sustentar as múltiplas vozes até que houvesse condições favoráveis para que novas descrições de si e do outro fossem produzidas.

Nesse sentido, o grupo funciona como uma fonte geradora de possibilidades insuspeitadas. É particularmente auspiciosa e transformadora a possibilidade de doar novos sentidos às experiências dilacerantes que são vivenciadas no contato com pacientes e familiares, aumentando a tolerância às diferenças, o que resulta numa maior capacidade de fornecer continência às angústias dos pacientes.

A partir dessa compreensão ampliada, é possível construir modos de lidar com os impasses da relação preservando-se a capacidade de dialogar e acolher a alteridade. Pouco a pouco os membros da equipe tornam-se mais confiantes em si mesmos e mais esperançosos na possibilidade de tratamento. Assumem uma postura ativa e comprometida, apropriando-se do cuidado, podendo ajudar pacientes e familiares a assumirem responsabilidade pela parte que lhes cabe no problema, sem circunscrever a dificuldade exclusivamente à esfera pessoal da pessoa cometida. Essa transformação é facilitada quando todos encontram a escuta atenta e a aceitação incondicional de colegas genuinamente interessados em compreendê-los.

\section{5- RELAÇÕES COM OUTROS PROFIS- SIONAIS}

Freqüentemente, a interação se dá com profissionais de saúde mental que não são integrantes do GRATA, mas que compartilham parte do seguimento de um paciente atendido pelo serviço. A título de ilustração, transcrevemos abaixo a mensagem recebida de uma psicoterapeuta que acompanha uma paciente em sua cidade de origem. Ela se dirige a uma psicóloga do serviço, que a havia contatado em nome da equi- 
pe, visando promover uma integração da assistência oferecida:

"Fiquei feliz com sua atenção. Na verdade, tenho uma maior experiência no tratamento de crianças. Essa é minha primeira paciente que apresenta esse transtorno. Como não vi progressos em seu quadro, fiquei muito preocupada e com medo de não poder ajudá-la, por isso pensei em encaminhá-la para [cidade maior].

Mas já não sei se é uma boa idéia, pois ela já me disse que poderá ir sozinha, e eu não sei o que ela poderá fazer lá.

No momento estou trabalhando com ela sobre a questão de sua impulsividade e suas relações (com família, amigos, rapazes, etc.). Mas é uma paciente com grande resistência ao tratamento e acredito que a família precise ser trabalhada também.

Estava discutindo alguns casos com um amigo médico, que trabalha também no posto de saúde, e ele me perguntou o motivo para ela usar "amplictil", se há possibilidade de um quadro psicótico associado. O que você acha? Ou o amplictil foi usado para conter os vômitos (pode ser usado para isso, não?). Além disso, a paciente apresenta, em alguns momentos, abuso de álcool, chegando a desmaiar em alguns finais de semana, segundo seus próprios relatos.

Devido a essa preocupação, acredito que continuarei com a paciente, mas preciso de sua ajuda. É um caso que estou levando para supervisão e ando lendo muito sobre o assunto.

Conto com você!

Um abraço."

\section{6- CONSIDERAÇÕES FINAIS}

As reflexões esboçadas no presente estudo apontam para a relevância do aprendizado na (e graças à) interação interprofissional. Quando se pensa a formação para a área de saúde, o foco nas questões do entretecer coletivo do saber-fazer é um requisito fundamental, sobretudo quando se pensa na perspectiva da clínica ampliada para uma atenção integral à saúde.

Os profissionais que integram uma equipe interdisciplinar são participantes privilegiados para a compreensão da complexidade envolvida no processo saúde-doença. Dos membros de uma equipe se exige uma postura de co-responsabilização e engajamento junto às famílias assistidas na busca de soluções para seu sofrimento e posições de maior conforto para todos. Acreditamos ser estas as bases para a construção do vínculo com essas famílias que apresentam, através da expressão sintomatológica do familiar acometido, o drama existencial que, de um modo ou de outro, acomete a todos, em suas diferentes configurações.

A busca de suporte emocional para a equipe implica no reconhecimento da necessidade dos profissionais envolvidos manterem um constante diálogo entre si (nível interpsíquico) e consigo mesmos (nível intrapsíquico), para assegurar um bom planejamento e prognóstico dos casos. Nessa ótica considera-se que o trabalho em equipe multidisciplinar oferece uma ferramenta ímpar seja para o alcance de bons resultados terapêuticos, seja para o avanço do tratamento na clínica dos transtornos alimentares. São inúmeras as potencialidades de construção de um conhecimento vivo e dinâmico entretecido a partir da convergência de múltiplos pontos de vista.

Para a reformulação do modo de produzir saúde é necessário um trabalho permanente de construção, desconstrução e reconstrução das práticas de saúde. Neste estudo propomos que a equipe, pensada enquanto grupo, é um reservatório social de recursos, criando e recriando possibilidades, na medida em que possa se recriar a cada encontro. É na espessura do encontro que se dão as transformações necessárias do instituído, para que se possa abrigar o novo em seu movimento nascente, gerando o instituinte da organização de saúde. Nesses termos, a equipe é pensada como um campo fértil para aquisição de habilidades e competências para atenção integral à saúde. É um celeiro fecundo para a formação de profissionais implicados com a mudança dos modelos de atenção à saúde e de ensino-aprendizagem. Tendo em vista esses pressupostos, propomos que a abordagem interdisciplinar é a que mais se aproxima da visão da complexidade que caracteriza os cuidados em saúde, numa tentativa de superação do enfoque biomédico, remediativo e fragmentado.

\section{AGRADECIMENTOS}

A todos os membros do GRATA, os atuais e aqueles que já não estão mais conosco, que a todo momento ajudam a escrever e reescrever esta história. 
Silva LM, Santos MA. Building bridges: a multidisciplinary team experience report on eating disorders. Medicina (Ribeirão Preto) 2006; 39 (3): 415-24.

ABSTRACT: The aim of this study is to describe the multi and interdisciplinary experience of a health workers team named Eating Disorders Care Group (EDCG / GRATA in Portuguese). This group is carried out in the Nutrology Ambulatory of the University Hospital of the Medical School of Ribeirão Preto, São Paulo University, Brazil. This paper focuses on the human resources and the multiple ways of coping with the practical situations of care in both hospital and outpatient clinic context. The model of care proposed by GRATA is described as an example of a praxis that elects the interdisciplinary approach as a guideline for the construction of knowledge and health intervention considering the multiple dimensions of the ill-health process. The living knowledge is constructed from the convergence of different disciplinary perspectives. Some experiences are reported in order to illustrate the comprehensive intervention in health care. Care, teaching and research development are integrated for the construction of a care practice. The health workers team has with time developed a commitment to understand the concrete life conditions and the interest of the assisted population. It is concluded that the interdisciplinary approach is the most appropriate to tackle the complexity of eating disorders and overcome the biomedical model of health care.

Keywords: Multidisciplinary Team. Eating Disorders. Anorexia Nervosa. Bulimia Nervosa.

\section{REFERÊNCIAS}

1 - Santos MA, Oliveira EA, Moscheta MS, Ribeiro RPP, Santos, JE. "Mulheres plenas de vazio": os aspectos familiares da anorexia nervosa. Vínculo: Rev NESME 2004; 1: 46-51.

2 - Cordás TA. Transtornos alimentares em discussão. Rev Bras Psiquiatr 2001; 23 (4): 178-9.

3 - American Psychiatry Association. Manual Diagnóstico e Estatístico dos Transtornos Mentais (DSM-IV). Trad. de D. Batista. Porto Alegre: Artes Médicas. 1991.

4 - Santos MA, Silva LM, Oliveira EA, Ribeiro RPP, Santos JE. Do viver com fome à fome de viver: psicoterapia e anorexia. II Congresso da Sociedade de Psicoterapias Analíticas Grupais do Estado de São Paulo (SPAGESP), I Encontro de Saúde Mental da Região de Ribeirão Preto e VIII Jornada do Núcleo de Estudos em Saúde Mental e Psicanálise das Configurações Vinculares (NESME). [CD]. Ribeirão Preto-SP. 2004; 366-369.

5 - Ribeiro RPP, Santos PCM, Santos JE. Distúrbios da conduta alimentar: anorexia e bulimia nervosas. Medicina, Ribeirão Preto 1998; 31: 45-53.

6 - Fiates GMR, Salles RK. Fatores de risco para o desenvolvimento de distúrbios alimentares: um estudo em universitárias. Rev Nutr, Campinas 2001; 14 (Supl.): 3-6.

7 - Nunes MAA, Fasolo C, Braga C, Somenzi, L, Azevedo, R. Anorexia nervosa: relato de caso. J Bras Psiquiatr 1995; 44 (Supl 1), S12-S15.

8 - Le Grange D. Family therapy for adolescent anorexia nervosa. J Clin Psychol 1999; 55 (6): 727-39.
9 - Santos RK. Anorexia nervosa na adolescência: concepções sobre a evolução do transtorno, o tratamento e suas repercussões psicossociais. [Monografia], Ribeirão Preto: Faculdade de Filosofia, Ciências e Letras de Ribeirão Preto - USP; 2000.

10 - Pinzon V, Gonzaga AP, Cobelo A, Labaddia E, Belluzzo P, Fleitlich-Bilyk B. Peculiaridades do tratamento da anorexia e da bulimia nervosa na adolescência: a experiência do PROTAD. Rev Psiquiatr Clin 2004; 31(4): 167-9.

11 - Nunes ED. A questão da interdisciplinaridade no estudo da saúde coletiva e o papel das ciências sociais. In: Canequi AM, org. Dilemas e desafios das ciências sociais na saúde coletiva. São Paulo-Rio de Janeiro: Hucitec-Abrasco; 1995. p. 95-115.

12 - Morin E. A religação dos saberes: o desafio do século XXI. Rio de Janeiro: Bertrand Brasil; 2001.

13 - Bó DEB, Barbosa R. Anorexia, bulimia e família: uma experiência com trabalho em grupo. J Bras Psiquiatr 1999; 12; 533-7.

14 - Santos MA. O trabalho em grupo na instituição hospitalar: acompanhamento psicológico de apoio ao familiar. Rev SPAGESP 2002; 3: 68-73.

15 - Santos RK, Mouraria CG, Soares IVB, Prizanteli CC, Bighetti F, Godoy RSP, Ribeiro RPP, Santos MA. Grupo de apoio psicológico aos familiares de portadores de anorexia e bulimia nervosa. Rev SPAGESP 2002; 3: 139-43.

16 - Cecílio LCO. As necessidades de saúde como conceito estruturante na luta pela integralidade e eqüidade na atenção em saúde. In: Pinheiro R, Mattos RA. Os sentidos da integralidade na atenção e cuidado à saúde. Rio de Janeiro: Abrasco; 2001. p. 113-26. 